\title{
Frequency of Vocal Cord Paralysis in Thyroidectomy
}

\author{
WAQAS JAVAID ${ }^{1}$, MIRZA MUHAMMAD SARWAR ${ }^{2}$, MUHAMMAD USMAN KHALID AMIN ${ }^{3}$, WAJIHA KHIZER ${ }^{4}$, MARYAM \\ FATIMA ${ }^{5}$ \\ ${ }^{1}$ Assistant Professor ENT, Fatima Jinnah Medical University, Lahore. \\ ${ }^{2}$ Associate Professor ENT, Fatima Jinnah Medical University, Lahore. \\ ${ }^{3}$ Senior Registrar, ENT, Fatima Jinnah Medical University, Lahore. \\ ${ }^{4}$ PGR ENT, Fatima Jinnah Medical University, Lahore. \\ ${ }^{5}$ WMOENT, Fatima Jinnah Medical University, Lahore. \\ Correspondence to Dr. Waqas Javaid, Email: waqas221@hotmail.com, Cell 03154269193
}

\begin{abstract}
Back ground: Recurrent laryngeal nerves being adjacent to the thyroid glands are prone to surgical trauma by thyroid surgery done for thyroid disease leading to vocal cord paralysis.

Aim: To determine frequency of vocal cord paralysis in thyroidectomy

Methodology: This is a descriptive cases series was completed in 6 months [December 4, 2019 till June 4, 2020] at Department ENT, Sir Ganga Ram hospital Lahore. The sample technique used is non-probability consecutive sampling .All 170 patients meeting inclusion criteria were inducted in the study from ENT SGR hospital, Lahore.

Results: The mean age of all patients was $39.52 \pm 11.30$ years with minimum and maximum age as 20 and 60 years. There were $91(53.5 \%)$ cases that were $20-40$ years old and $79(46.5 \%)$ cases were $41-60$ years old. There were $62(36.5 \%)$ male and $108(63.5 \%)$ female cases with higher female to male ratio. In $96(56.5 \%)$ cases left side and in $74(43.5 \%)$ cases right side was involved. There were $37(21.8 \%)$ who had vocal cord paralysis while $133(78.2 \%)$ cases did not have vocal cord paralysis.

Conclusion: It is concluded that high number of patients i.e. $21.8 \%$ had vocal cord paralysis, so in future ENT surgeons should adopt safety measures for prevention of VCP such anatomical considerations of the sensitive area Keywords: ENT, thyroidectomy, complications, vocal cord paralysis
\end{abstract}

\section{INTRODUCTION}

Thyroidectomy is one of the most frequently performed general surgery procedures. Indications for thyroid surgery ${ }^{1}$ are hyperthyroidism, thyroid swellings, with a prevalence of between 4.2 to $51.3 \%$ and thyroid cancers $^{2}$.

Traditionally, thyroid surgery has been an inpatient procedure due to the risk of several well-documented complications $^{3}$. Vocal cord paresis or paralysis (VCP) due to iatrogenic injury of the recurrent laryngeal nerve is one of the main problems in thyroid surgery ${ }^{4,5}$. However, $30 \%-$ $40 \%$ of patients may be asymptomatic, and imaging findings may be the first indication of paralysis. ${ }^{6}$ It is important to carefully inspect the entire course of the vagus and recurrent laryngeal nerves to exclude any causative pathology because the relatively benign finding of VCP may herald a more ominous underlying disease ${ }^{7}$. A description of relevant anatomy and imaging evaluation of VCP is first discussed, followed by a discussion of pathologic conditions that result in $\mathrm{VCP}^{8}$.

Thyroidectomy is a common surgical procedure, and since postoperative vocal cord paresis or palsy (VCP) is a significant contributor to medico-legal litigation in thyroid surgery, information on the patient's preoperative and postoperative vocal cord status is regarded essential ${ }^{9}$. However, there is some disagreement on whether or not regular preoperative and to some degree, postoperative laryngeal examinations of the vocal cords are necessary ${ }^{10}$ nerve (RLN) to avoid a tracheostomy. Those in favor of regular preoperative testing claim that in the event of a preoperative VCP, the patient should be properly counselled prior to surgery, the surgeon should take

Received on 24-11-2020
Accepted on 14-02-2021

"special" care with the contralateral recurrent laryngeal, and that would indicate thyroid cancer. ${ }^{11}$ Those who oppose routine preoperative examination argue that since preoperative VCP is uncommon, the vast majority of patients (especially those with no voice symptoms or prior neck operations) are subjected to unnecessary laryngeal examinatio ${ }^{10}$

Moreover, laryngeal examination causes discomfort to the patients and that could lead to patient's poor cooperation to the procedure ${ }^{12}$. Transcutaneous laryngeal ultrasonography (TLUSG) performed by the surgeons has shown to be a encouraging non-invasive mode of vocal cord examination ${ }^{13}$. TLUSG can assess up to 87 percent of the vocal cords, according to one report, which concluded that TLUSG could be used to pick patients for a preoperative direct laryngoscopy $(D L)^{14}$. These frequencies of VCP was lesser than as we found. The results of a robotic thyroidectomy are close to those of a traditional open thyroidectomy in terms of voice function ${ }^{17}$.

\section{SUBJECTS AND METHODS}

This is a descriptive cases series and it was conducted in 6 months [December 4, 2019 till June 4, 2020] at Department ENT, Sir Ganga Ram Hospital Lahore. The sample technique used is non-probability consecutive sampling. All 170 patients meeting inclusion criteria were inducted in the study from ENT SGR Hospital, Lahore using expected frequency of vocal cord paralysis in thyroidectomy i.e., $20.5 \%{ }^{9}$ at $95 \%$ confidence level and $6.5 \%$ margin of error. Patients were given description of the surgery and then were taken in study after taking informed consent from patients or attendants meeting inclusion criteria. 
Demographic details such as age, gender and contact details were obtained for all patients. All surgeries were done under general anesthesia and surgeries were doneby a single senior surgeon having more than 5 years' experience after post-graduation to avoid surgical baise. VCP after 1 week of thyroidectomy was determined on $70^{\circ}$ rigid laryngosopy. Collected patient's data was entered and analyzed using computer software, SPSS version 20. Qualitative data such as gender, side involved (left or right) and frequency of VCP was presented in form of frequency and percentage. Mean \pm S.D was used for quantitative data like age. Data was stratified over age, gender, procedure done and diagnosis and side involved to overcome the effect modifiers. Post stratification Chi- test square test was used after stratification. A $p$ value $\leq 0.05$ is considered statistically significant.

\section{RESULTS}

The mean age of all patients was $39.52 \pm 11.30$ years with minimum and maximum age as 20 and 60 years (Table 1 ). There were $91(53.5 \%)$ cases who were $20-40$ years old and $79(46.5 \%)$ cases were $41-60$ years old (Fig- 1$)$.

There were $62(36.5 \%)$ male and $108(63.5 \%)$ female cases with higher female to male ratio (Fig-2).

In $96(56.5 \%)$ cases left side and in $74(43.5 \%)$ cases right side was involved (Fig-3).

There were $37(21.8 \%)$ who had vocal cord paralysis while $133(78.2 \%)$ cases did not have vocal cord paralysis (Fig-4).

Stratification

- When data was stratified for age, among 20-40 years of age group there were $20(22 \%)$ cases who had vocal cord paralysis and among 41-60 years of age, $17(21.5 \%)$ cases who had palsy of vocal cord. The frequency of vocal cord palsy was statistically same in both age groups, p-value $>0.05$ (Table 2 )

- There were 18(29\%) male and 19(17.6\%) female cases who had vocal cord palsy, the frequency of vocal cord paralysis was statistically same in both gender, p-value $>0.05$ (Table 3)

- In cases who had left side involved, 23(24\%) cases had vocal cord paralysis and in cases who had right side involved 14(18.9\%) cases had vocal cord paralysis. the frequency of vocal cord palsy was statistically same in sided involved, $p$-value $>0.05$ (Table 4).

- According to diagnosis, in cases who had goiter $33(20.2 \%)$ had vocal cord paralysis and $4(57.1 \%)$ cases who cancer and had vocal cord paralysis. The frequency of vocal cord palsy was statistically higher in cases who had cancer as compared to goiter, $p$-value $<0.05$ (Table -5).

Note: Data was not stratified for procedure, as all cases had convention thyroidectomy.

Table 1: Descriptive statistics of age (years)

\begin{tabular}{|l|l|}
\hline Age (years) & \\
\hline Mean & 39.52 \\
\hline S.D & 11.30 \\
\hline Range & 40.00 \\
\hline Minimum & 20.00 \\
\hline Maximum & 60.00 \\
\hline
\end{tabular}
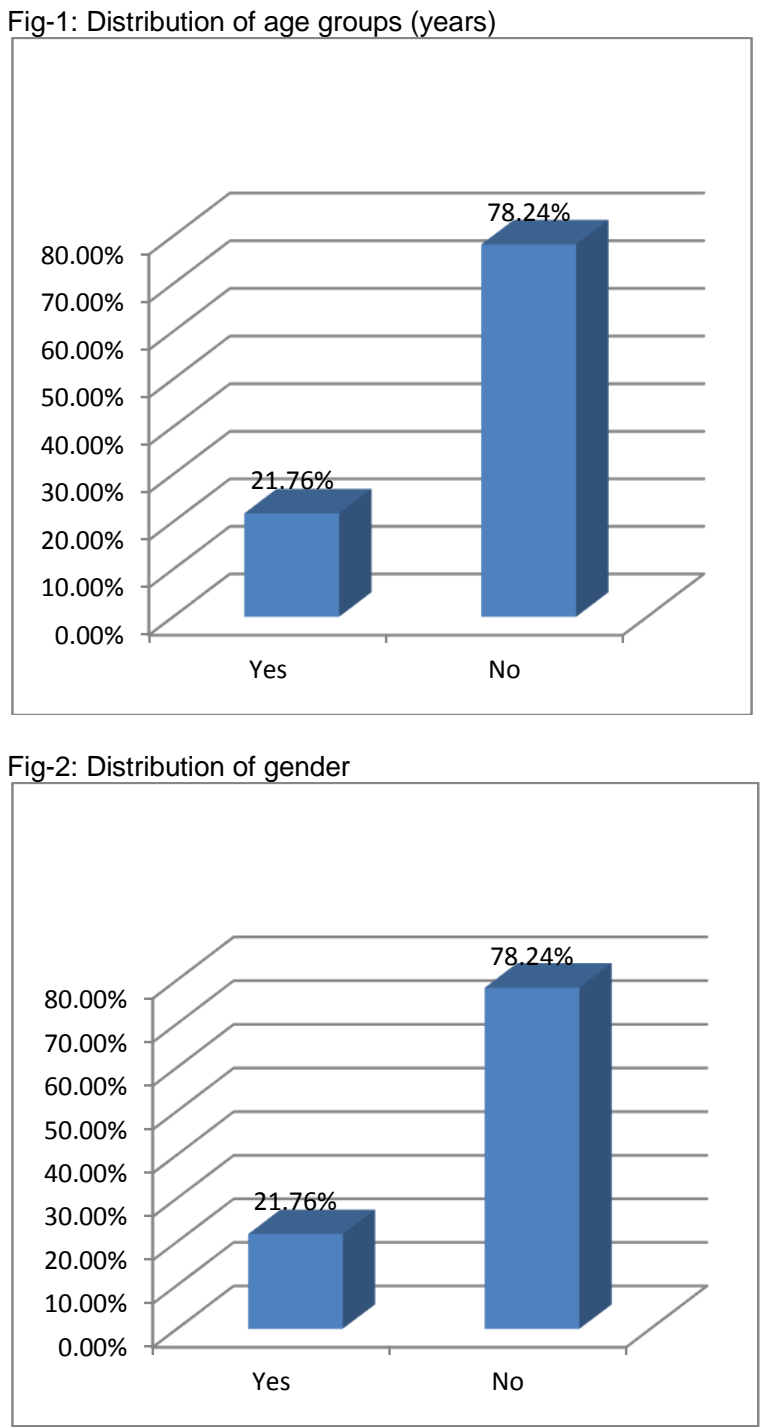

Fig. 3: Distribution of side involvement

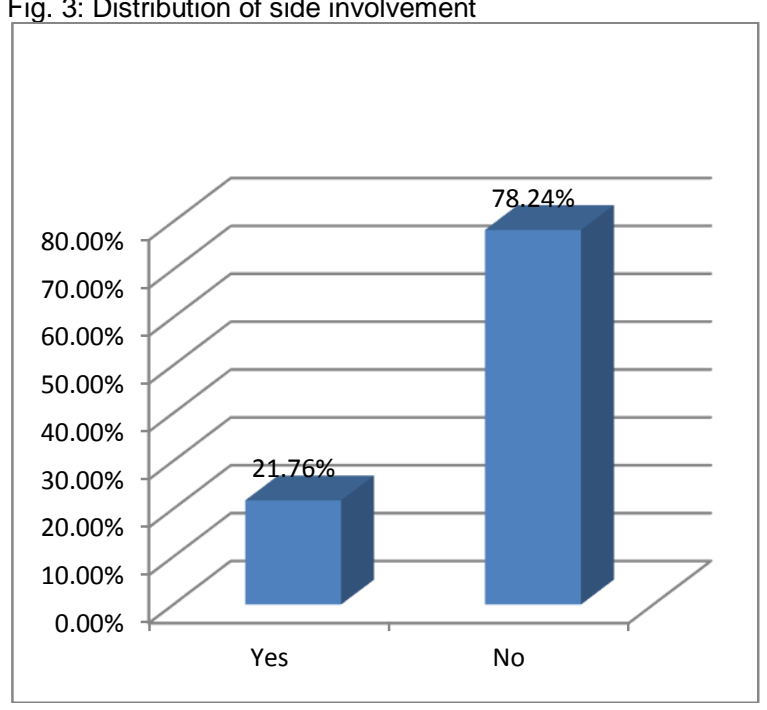


Fig. 4: Distribution of vocal cord paralysis

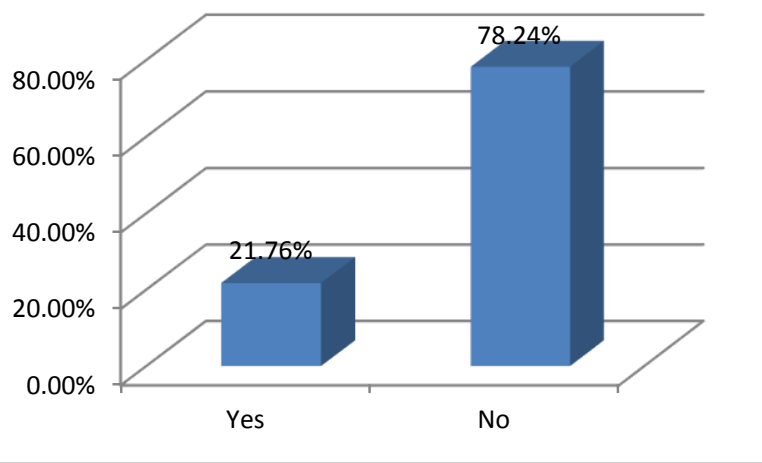

Table 2: Comparison of Vocal cord paralysis with respect to age groups (years)

\begin{tabular}{|l|c|c|c|}
\hline \multirow{2}{*}{$\begin{array}{l}\text { Age groups } \\
\text { (years) }\end{array}$} & \multicolumn{2}{|c|}{ Vocal cord paralysis } & \multirow{2}{*}{ Total } \\
\cline { 2 - 3 } & Yes & No & \\
\hline $20-40$ & $20(22 \%)$ & $71(78 \%)$ & $91(100 \%)$ \\
\hline $41-60$ & $17(21.5 \%)$ & $62(78.5 \%)$ & $79(100 \%)$ \\
\hline Total & $37(21.8 \%)$ & $133(78.2 \%)$ & $170(100 \%)$ \\
\hline
\end{tabular}

Chi-square $=0.005 \mathrm{P}$-value $=0.942$ (Insignificant)

Table-3: Comparison of vocal cord paralysis with respect to gender

\begin{tabular}{|l|c|c|c|}
\hline \multirow{2}{*}{ Gender } & \multicolumn{2}{|c|}{ Vocal cord paralysis } & \multirow{2}{*}{ Total } \\
\cline { 2 - 3 } & Yes & No & \\
\hline Male & $18(29 \%)$ & $44(71 \%)$ & $62(100 \%)$ \\
\hline Female & $19(17.6 \%)$ & $89(82.4 \%)$ & $108(100 \%)$ \\
\hline Total & $37(21.8 \%)$ & $133(78.2 \%)$ & $170(100 \%)$ \\
\hline
\end{tabular}

Chi-square $=3.027 \mathrm{P}$-value $=0.082($ Insignificant $)$

Table 4: Comparison of vocal cord paralysis with respect to side involvement

\begin{tabular}{|l|c|c|c|}
\hline \multirow{2}{*}{ Side } & \multicolumn{2}{|c|}{ Vocal cord paralysis } & \multirow{2}{*}{ Total } \\
\cline { 2 - 3 } & Yes & No & \\
\hline Left & $23(24 \%)$ & $73(76 \%)$ & $96(100 \%)$ \\
\hline Right & $14(18.9 \%)$ & $60(81.1 \%)$ & $74(100 \%)$ \\
\hline Total & $37(21.8 \%)$ & $133(78.2 \%)$ & $170(100 \%)$ \\
\hline
\end{tabular}

Chi-square $=0.623 \mathrm{P}$-value $=0.430$ (Insignificant)

Table 5: Comparison of Vocal cord paralysis with respect to diagnosis

\begin{tabular}{|l|c|c|c|}
\hline \multirow{2}{*}{ Diagnosis } & \multicolumn{2}{|c|}{ Vocal cord paralysis } & \multirow{2}{*}{ Total } \\
\cline { 2 - 3 } & Yes & No & \\
\hline Goiter & $33(20.2 \%)$ & $130(79.8 \%)$ & $163(100 \%)$ \\
\hline Cancer & $4(57.1 \%)$ & $3(42.9 \%)$ & $7(100 \%)$ \\
\hline Total & $37(21.8 \%)$ & $133(78.2 \%)$ & $170(100 \%)$ \\
\hline
\end{tabular}

Chi-square $=5.366 \mathrm{P}$-value $=0.021$ (Insignificant $)$

\section{DISCUSSION}

Vocal cord paralysis (VCP) refers to loss of active movement of the true vocal cord secondary to disruption of laryngeal motor innervation, which is supplied by the superior and recurrent laryngeal nerves that arise from the vagus nerve (cranial nerve $X$ ). Thus, VCP can be caused by pathology anywhere along the course of the vagus or recurrent laryngeal nerves, from the motor nuclei of the vagus in the brain stem to the level of innervation at the larynx.

In this study the mean age of all patients was $39.52 \pm$ 11.30 years with minimum and maximum age as 20 and 60 years. There were $91(53.5 \%)$ cases who were $20-40$ years old and $79(46.5 \%)$ cases were $41-60$ years old. There were $62(36.5 \%)$ male and $108(63.5 \%)$ female cases with higher female to male ratio. In $96(56.5 \%)$ cases left side and in $74(43.5 \%)$ cases right side was involved. There were $37(21.8 \%)$ who had vocal cord paralysis while $133(78.2 \%)$ cases did not have vocal cord paralysis. Recently a study aimed to assess the incidence of transient/permanent postoperative RLN injuries after thyroid and parathyroid surgery in the present cohort, to observe the timing of recovery, and to identify risk factors for permanent RLN injury after thyroidectomy. The result cohort included 451 thyroidectomies (756 nerves at risk) and 197 parathyroidectomies (276 nerves at risk). There were 63 postoperative vocal cord pareses after thyroidectomy and 13 after parathyroidectomy. Sixty-nine were transient $(10.6 \%)$ and 7 permanent. The study involved 88 consecutive patients who underwent thyroid surgery between May 2009 and December 2009; 46 patients underwent a conventional open thyroidectomy, and 42 underwent a robotic thyroidectomy. The conventional open and robotic thyroidectomy groups were found to have similar levels of dysfunction at 1 week after surgery, except for jitter, which was greater in the robotic group. For both groups, any such dysfunction spontaneously resolved by 3 months after surgery, and there were no significant differences between the groups in terms of any voice function parameter. So, the study has concluded that voice dysfunction was present after both open and robotic thyroidectomy (without any evident laryngeal nerve injury.

\section{CONCLUSION}

It is concluded that high number of patients i.e. $21.8 \%$ had vocal cord paralysis, so in future ENT surgeons should adopt safety measures for prevention of VCP such anatomical considerations of the sensitive area.

\section{REFERENCES}

1. Memon ZA, Ahmed G, Khan SR, Khalid M, Sultan N. Postoperative use of drain in thyroid lobectomy-a randomized clinical trial conducted at Civil Hospital, Karachi, Pakistan. Thyroid Res. 2012;5(1):9-14.

2. Prichard $R$. The routine use of post-operative drains in thyroid surgery: an outdated concept. Ir Med J. 2010;103(1):26-7.

3. Sun GH, DeMonner S, Davis MM. Epidemiological and economic trends in inpatient and outpatient thyroidectomy in the United States, 1996-2006. Thyroid. 2013;23(6):727-33.

4. Zakaria HM, Al Awad NA, Al Kreedes AS, Al-Mulhim A, AlSharway MA, Hadi MA, et al. Recurrent laryngeal nerve injury in thyroid surgery. Oman Med J. 2011;26(1):34-8.

5. Lang BH-H, Chu KK-W, Tsang RK-Y, Wong KP, Wong BY$\mathrm{H}$. Evaluating the incidence, clinical significance and predictors for vocal cord palsy and incidental laryngopharyngeal conditions before elective thyroidectomy: is there a case for routine laryngoscopic examination? World J Surg. 2014;38(2):385-91. 
6. Dankbaar J, Pameijer F. Vocal cord paralysis: anatomy, imaging and pathology. Insights Imaging. 2014;5(6):743-51.

7. Richardson BE, Bastian RW. Clinical evaluation of vocal fold paralysis. Otolaryngol Clin North Am. 2004;37(1):45-58.

8. Rosenthal LHS, Benninger MS, Deeb RH. Vocal fold immobility: a longitudinal analysis of etiology over 20 years. Laryngoscope. 2007;117(10):1864-70

9. Abadin SS, Kaplan EL, Angelos P. Malpractice litigation after thyroid surgery: the role of recurrent laryngeal nerve injuries, 1989-2009. Surgery. 2010;148(4):718-23.

10. Schlosser K, Zeuner M, Wagner M, Slater EP, Fernández $\mathrm{ED}$, Rothmund $\mathrm{M}$, et al. Laryngoscopy in thyroid surgeryessential standard or unnecessary routine? Surgery. 2007;142(6):858-64. e2.

11. Randolph GW, Kamani D. The importance of preoperative laryngoscopy in patients undergoing thyroidectomy: voice, vocal cord function, and the preoperative detection of invasive thyroid malignancy. Surgery. 2006;139(3):357-62.

12. Paul BC, Rafii B, Achlatis $S$, Amin MR, Branski RC. Morbidity and patient perception of flexible laryngoscopy. Ann Otol Rhinol Laryngol. 2012;121(11):708-13.
13. Wang C-P, Chen T-C, Yang T-L, Chen C-N, Lin C-F, Lou P$J$, et al. Transcutaneous ultrasound for evaluation of vocal fold movement in patients with thyroid disease. Eur $\mathrm{J}$ Radiol. 2012;81(3):e288-e91.

14. Cheng S-P, Lee J-J, Liu T-P, Lee K-S, Liu C-L. Preoperative ultrasonography assessment of vocal cord movement during thyroid and parathyroid surgery. World J Surg. 2012;36(10):2509-15.

15. Wong K-P, Lang BH-H, Ng S-H, Cheung C-Y, Chan CT-Y, Lo C-Y. A prospective, assessor-blind evaluation of surgeonperformed transcutaneous laryngeal ultrasonography in vocal cord examination before and after thyroidectomy. Surgery. 2013;154(6):1158-65

16. Joliat G-R, Guarnero V, Demartines N, Schweizer V, Matter $M$. Recurrent laryngeal nerve injury after thyroid and parathyroid surgery: Incidence and postoperative evolution assessment. Medicine. 2017;96(17)

17. Lee J, Na KY, Kim RM, Oh Y, Lee JH, Lee J, et al Postoperative functional voice changes after conventional open or robotic thyroidectomy: a prospective trial. Ann Surg Oncol. 2012;19(9):2963-70. 